\title{
SIMPLE Design Framework for Teaching Development Across STEM
}

\section{Prof. Jill K Nelson, George Mason University}

Jill Nelson is an associate professor in the Department of Electrical and Computer Engineering at George Mason University. She earned a BS in Electrical Engineering and a BA in Economics from Rice University in 1998. She attended the University of Illinois at Urbana-Champaign for graduate study, earning an MS and PhD in Electrical Engineering in 2001 and 2005, respectively. Dr. Nelson's research focus is in statistical signal processing, specifically detection and estimation for applications in target tracking and physical layer communications. Her work on target detection and tracking is funded by the Office of Naval Research. Dr. Nelson is a 2010 recipient of the NSF CAREER Award. She is a member of Phi Beta Kappa, Tau Beta Pi, Eta Kappa Nu, and the IEEE Signal Processing, Communications, and Education Societies.

\section{Dr. Margret Hjalmarson, George Mason University}

Margret Hjalmarson is an Associate Professor in the Graduate School of Education at George Mason University and currently a Program Officer in the Division of Research on Learning in Formal and Informal Settings at the National Science Foundation. Her research interests include engineering education, mathematics education, faculty development and mathematics teacher leadership.

\section{Dr. Lori C. Bland, George Mason University}

Lori C. Bland, Ph.D., is an associate professor at George Mason University. She teaches courses in educational assessment, program evaluation, and data-driven decision-making. Bland received her Ph.D. in Educational Psychology from the University of Virginia. Her current research focuses on identifying, examining, and assessing learning and professional outcomes in formal and informal learning environments in $\mathrm{K}-12$, higher education, and the workforce; how data is used from assessments to inform decisionmaking; and the application of assessment or evaluation methods to solve educational problems.

\section{Prof. Anastasia P Samaras, George Mason University, VA USA}

ANASTASIA P. SAMARAS is Professor of Education in the College of Education and Human Development at George Mason University, USA. She is an educational researcher and pedagogical scholar with signature work in self-study research methodology including co-editor of Polyvocal Professional Learning through Self-Study Research (2015) and author of Self-Study Teacher Research (2011) and lead editor of Learning Communities In Practice (2008). She is recipient of the Dissertation Research Award, University of Virginia, the Outstanding Scholar Award, University of Maryland, a Fulbright Scholar, and a Visiting Self-study Scholar. She served as chair of S-STEP from 2013-2015 and is a current Co-PI of two National Science Foundation (NSF) funded grants: Designing Teaching: Scaling up the SIMPLE Design Framework for Interactive Teaching Development and a research initiation grant: Student-directed differentiated learning in college-level engineering education. Her research centers on facilitating and studying her role in faculty development self-study collaboratives. 


\section{SIMPLE Design Framework for Teaching Development Across STEM}

\section{Introduction}

Extensive research has shown the benefits of interactive teaching for student learning and retention ${ }^{1}$. However, significant barriers exist to broadening the use of interactive techniques in college classrooms, particularly within STEM fields. The challenges to changing teaching practice in undergraduate STEM are relatively well known ${ }^{1}$. These include faculty lack of knowledge of new teaching strategies, instructor resistance to change, and how faculty balance teaching with other competing commitments like research. In this paper, we do not attempt to resolve all of these, often systemic, challenges; rather, we put forward a model for teaching development groups that is grounded in research about faculty development. As a foundational idea, it proposes that learning to teach, like learning other things, is a process that will take time and support from others. It takes up the idea that teaching is a developmental process that will not necessarily change quickly but rather comprises a series of design decisions that are made over multiple semesters.

Significant research about faculty development of interactive teaching practices has been conducted ${ }^{2-5}$. Earlier work by McKenna, Yalvac, and Light examined how to create collaborative partnerships between engineering faculty and learning scientists to encourage collaborative, reflective, and improved teaching. They state, "An extension of this work would be to examine the trajectory of change in teaching approaches, that is, to investigate the process of change.” (p. 25) ${ }^{4}$ We expect learning and change to happen through faculty development, and we propose a framework for scaffolding that process of change much like engineering education research has proposed constructing learning environments for students - as collaborative, design-focused environments that balance knowledge of the discipline (in this case teaching) with practice of the discipline.

We propose a framework for faculty teaching development groups that builds on other work in professional learning communities ${ }^{6-9}$. The SIMPLE Design framework, described in more detail below, provides a set of guiding principles for ongoing faculty development designed to support widespread use of evidence-based interactive teaching practices. The participants in the groups represent a range of expertise and background in their familiarity with and use of interactive teaching. All participants shared an interest in continuing to develop their teaching. This paper will describe the evolution of the most significant SIMPLE Design principles over two different NSF-funded projects. In the projects discussed here, we examine a collaborative, reflective process grounded in product development and in work with other STEM faculty who have an interest in improving and refining their teaching. Our guiding research question over both studies is: How can teaching development groups serve to support instructors in learning about and implementing interactive teaching strategies?

\section{The SIMPLE Design Framework}


The principal idea that frames both the SIMPLE Design framework and the decisions made about the design and implementation of this project is that teaching is a design process. Laurillard describes teaching as design (similar to engineering or architecture) in the sense that the teacher is attempting to change, respond, or influence the environment and the learning experience of other people ${ }^{10}$. This design perspective about teaching leads to questions about implementing strategies and examining how they operate in situ considering students, content, and other aspects of the teaching context that influence a teacher's decision-making. The design perspective also emphasizes the need for instructors to continuously assess and revise their teaching practice for whether it is meeting a variety of possible objectives including student achievement, learning, motivation, and engagement.

The SIMPLE Design framework for ongoing faculty development includes six researchbased principles that have emerged from our work with engineering faculty in a prior NSF IEECI project ${ }^{9,11}$ and are now being applied to other STEM disciplines in an ongoing NSF WIDER project. The first project focused only on creating professional learning communities; the more specific principles emerged from that work when we were conceptualizing the second project. In this paper, we explain how the principles guide and describe the organization of teaching development groups and how the most significant of them have evolved through multiple projects. We describe and discuss how the SIMPLE principles operate across diverse teaching development groups as they are broadly interpreted. The six principles are summarized in Table 1.

\begin{tabular}{|l|l|}
\hline Principle & Description \\
\hline Sustainable & $\begin{array}{l}\text { The groups meet on an ongoing, regular basis. The support is } \\
\text { provided in discipline-driven groups of 4-6 instructors. }\end{array}$ \\
\hline $\begin{array}{l}\text { Incremental } \\
\text { Change }\end{array}$ & $\begin{array}{l}\text { Participants agree to make at least a small change or } \\
\text { innovation in their teaching, a change that fits their course and } \\
\text { comfort with trying new practices. }\end{array}$ \\
\hline Mentoring & $\begin{array}{l}\text { The small group structure provides a comfortable } \\
\text { environment for sharing ideas, learning from others, and } \\
\text { giving and receiving support for trying new teaching } \\
\text { practices. }\end{array}$ \\
\hline $\begin{array}{l}\text { People- } \\
\text { driven }\end{array}$ & $\begin{array}{l}\text { The groups are organized around the needs and interests } \\
\text { of STEM faculty. They are designed to meet faculty needs for } \\
\text { teaching in interactive learning environments in order to } \\
\text { improve the quality of student learning and engagement. }\end{array}$ \\
\hline $\begin{array}{l}\text { Learning } \\
\text { Environment }\end{array}$ & $\begin{array}{l}\text { Work is focused on the design and integration of more } \\
\text { interactive learning environments that move beyond } \\
\text { transmission pedagogies or direct instruction models. }\end{array}$ \\
\hline Design & $\begin{array}{l}\text { Participants agree to document their process of creating } \\
\text { interactive teaching practices by creating a design memo that } \\
\text { explains the innovation, the constraints and affordances of its } \\
\text { use, and examples of its application in the classroom. This } \\
\text { creates a sharable, external product and focuses participants' } \\
\text { work on the design of teaching. }\end{array}$ \\
\hline
\end{tabular}


Table 1: SIMPLE Design Principles

The SIMPLE Design framework is intentionally simple and focused as a theory of change, even though the process of changing teaching practice and implementing interactive teaching is complex. The simplicity and flexibility of the principles are intentional for creating an environment where risks in teaching (even small ones) are encouraged and supported. The principles are also simple in the sense that we see them as transferrable across multiple disciplines and contexts, even though the interactive teaching practices may be very distinctive between departments and among multiple levels of learning (e.g., early undergraduate, upper-level undergraduate, graduate, courses for majors vs. general education courses). The SIMPLE Design principles, while intentionally open to interpretation, also have few barriers to entry and limited start-up costs for those instructors who choose to explore their teaching with a small group in their local unit. While being flexible, the principles still provide a cohesive structure for supporting teaching development, as well as a means for helping faculty document their rationales and processes for change in a sharable fashion. We describe some of these features in earlier papers ${ }^{9,11,12}$.

A central feature of the SIMPLE Design framework is that instructors' discussion of their teaching innovations is done in small groups over time. We envisioned groups of four to six instructors that are from the same (or closely related) STEM departments. The smallness of the groups facilitates both conversation and scheduling. Group discussion centers on learning about new evidence-based techniques and trying and revising those techniques in the classroom. The most important characteristic of a potential participant is openness to talking about changes they might make to their teaching and willingness to try something new and interactive within an upcoming course. The recruitment of interested faculty was an intentional choice in order to enable a supportive environment. Recruiting faculty resistant to changing their teaching would be a longer-term goal than our projects encompass. Small groups provide both support and accountability as participants navigate implementation, assessment, and revision of new teaching strategies. Discussion within a discipline-specific group is also intended to help translate general recommendations for teaching and learning to a specific, disciplinary context such as science, mathematics, or engineering by engaging groups with common interests and expertise in a community of practice ${ }^{6}$.

As a second feature, we also ask instructors to write short design memos that describe the teaching strategy they are trying and their goals for that strategy. We have described the outline for the design memos we ask instructors to write to document the strategies they have selected in a previous paper ${ }^{13}$. The memos include describing the teaching strategy itself, explaining the rationale for the strategy within the particular context, describing how the strategy was implemented, and discussing what modifications the instructor might make next time they use the strategy. We incorporate the creation of design memos as part of the teaching development process for two reasons. First, writing a short and structured narrative about teaching should encourage the instructors to reflect about what they are trying to accomplish with new teaching strategies and continually think about how to improve them. Reflection about teaching is a necessary part of ongoing teaching 
development ${ }^{4}$. Second, the design memos provide an artifact that can be shared with other instructors to describe the kinds of strategies and changes they could consider making to their teaching ${ }^{13}$. This sharable artifact can then be used to focus the discussion in the teaching development groups.

\section{Study Context}

In this paper, we report on cumulative findings from two NSF-funded projects focused on faculty teaching development. We examine a collaborative, reflective process grounded in product development and work with other STEM faculty with an interest in improving and refining teaching. In the first project, teaching development groups were created within engineering programs at multiple institutions. In the second project, groups were created in several STEM departments, all at the same institution. Further details of each project are described below. An initial version of the SIMPLE Design principles emerged from the first project and formed the basis for the second project.

The first project, which we refer to here as SIMPLE Engineering, spanned two years and was focused exclusively on engineering instructors, primarily electrical engineering. The aim of the project was to study how ongoing teaching development groups can broaden the use of evidence-based teaching practices. The project began with the creation of a team of four electrical engineering faculty members, each from a different institution. The team held an in-person kickoff meeting and then met virtually via conference call on a monthly basis over the course of an academic year. Their goal during the year was to identify an interactive teaching strategy that would address a need in their classroom, implement that strategy, and document the process. The monthly conference calls provided an opportunity for them to share successes and challenges, ask questions, and provide feedback. Records of the monthly conference calls were kept as field notes that were read and edited in real time by the participants.

In the second year of SIMPLE Engineering, each team leader formed an engineering teaching development group at their home institution. The four local groups met regularly (anywhere from once a week to once a month) over an academic year. Through participation in the group, faculty learned about interactive teaching strategies (often through discussion of relevant articles, books, or videos), implemented a new strategy in their classes, and documented the process. The engineering teaching development groups included tenure-track and tenured faculty members, term instructors, and a graduate student who was fully responsible for teaching a course. The group leaders each wrote a descriptive narrative about their groups at the end of the project.

In SIMPLE STEM, a three-year project that is currently underway, we have expanded teaching development groups to operate within a variety of STEM fields at a single institution. The SIMPLE Design principles are used to guide the groups. The aim of the project is to support faculty use of evidence-based teaching practices and to study how the SIMPLE Design principles are enacted across different departments and different teaching development groups. In the first semester of SIMPLE STEM, STEM faculty members who would later become group leaders met monthly to become familiar with 
the SIMPLE Design model and with evidence-based teaching. During this training semester, they also focused on assessing, revising, and documenting a new strategy they were implementing in their classes to model the process they would lead in teaching development groups. During the following academic year, each leader formed and facilitated a teaching development group in their discipline. These groups are ongoing and evolving with the project. The fields represented in SIMPLE STEM groups include civil engineering, electrical engineering, computer science, physics and astronomy, mathematical sciences, and biology. In addition to leading their own groups, group leaders continue to participate in monthly meetings with the PIs and other leaders.

\section{Data Sources}

To answer our research question, we used two sets of data; one was collected from the SIMPLE Engineering project, and the other was collected from SIMPLE STEM. The former includes descriptive narratives that each group leader wrote about his/her group at the end of the project. In SIMPLE STEM, data collection was completed for the first year of groups' functioning and is underway for the second year. During the first year we collected mini-surveys of group leaders that were distributed at each group leader meeting; these meetings were also audio recorded. After the first year cycle was over, we conducted semi-structured interviews ${ }^{14}$ with both the leaders and group members. A total of 24 out of 30 participants agreeing to be interviewed including members of each group in the study. For the second (current) year of groups' functioning in SIMPLE STEM, data sources include audio recordings of the group leader meetings and mini-surveys of the leaders. We aimed to ensure that as many participants' perspectives and experiences as possible were considered and presented. Multiple data sources were used to triangulate the findings and conclusions.

\section{Lessons Learned from SIMPLE Engineering}

The understanding of faculty teaching development gained through SIMPLE Engineering informed the structure of SIMPLE STEM. The major characteristics of SIMPLE Engineering included small group, faculty development, and the creation of design memos. Toward the end of SIMPLE Engineering, the SIMPLE Design principles were formulated to describe more concretely the aspects of the prior work we found important in order to guide the organization of teaching development groups in the subsequent project. The SIMPLE Design principles are being explored further as they are expanded to include other STEM departments. Beyond the principles, however, other lessons learned in SIMPLE Engineering have been passed on as institutional wisdom to the ongoing SIMPLE STEM groups.

One common take-away from SIMPLE Engineering group leaders as they reflected on their experience leading a group was that scheduling is critical. Specifically, leaders reported that early scheduling of meetings was necessary for the sustainability of the group. Leaders strongly recommended scheduling all meetings for a semester at the start of the semester when participants' calendars were still relatively open. We believe this relates to the time challenges faculty face when balancing competing responsibilities. The 
practical reality is that meetings scheduled in advance are more likely to happen than meetings that are scheduled one by one. While this may seem like a small logistical detail, we encouraged groups in SIMPLE STEM to follow this recommendation, and groups that scheduled a full semester of meetings in advance were more likely to meet regularly than were those that did not.

Another lesson learned in SIMPLE Engineering and carried into SIMPLE STEM is the importance of the role of graduate students in the meetings. In some cases (across the two projects), graduate students were integral members of the teaching staff with their own courses to teach. In other departments, they served as teaching assistants in a course taught by a faculty instructor. In either case, participants' knowledge of their own department culture informed whether or not to invite graduate students into the group. In SIMPLE Engineering, we had one graduate student involved in one group. In SIMPLE STEM, we have had several graduate students involved in teaching development groups or in mentoring pairs with faculty instructors. We had not anticipated when we created the groups that graduate students might be involved, but we view this as a positive development.

\section{Shared Themes across SIMPLE Engineering and SIMPLE STEM Groups}

A strongly shared theme across teaching development groups in both the SIMPLE Engineering and SIMPLE STEM projects was the people-driven aspect. The peopledriven principle for SIMPLE can be enacted in a few different ways. The first meaning of people-driven is drawn from work in professional learning communities ${ }^{6}$ where the community work is driven by the participants in the community. This people-driven aspect ranges from the recruitment of new members by the group leaders to the structuring of a meeting schedule. As another aspect of people-driven, groups selected their own external resources to use if they felt they were useful. Driven by the interests of participants, some groups adopted a journal-club style format, while others used books on teaching to scaffold discussion, and others invited speakers with expertise in learning technologies or education research. Each group used external resources to varying degrees. We view these external resources as scaffolds to create structure, provide suggestions of evidence-based techniques, and prompt change. The people-driven principle may also appear in a more collaborative fashion. Some groups have chosen to address collective goals through their faculty development, e.g. redevelopment of a laboratory sequence, creation of a repository of institutional wisdom about teaching in the field, etc.

Another significant common theme across the two projects has been the formation of community. As a group leader wrote in SIMPLE Engineering, "The group was excited to form a community that would regularly discuss topics of common interest and be supportive of each others' teaching-related efforts." This theme of community development was continued into SIMPLE STEM. As one participant stated, "The atmosphere was really supportive and encouraging. Everybody who was there was there because they feel a kind of lack or need to change... maybe not a lack so much as that there is more that could be done, that we are not reaching the students as effectively as 
we could be.” One aspect of the community development was to support the design process of teaching. At the conclusion of SIMPLE Engineering, the group leaders described a cycle of semesters in which the ongoing support played a role. In the first semester of meeting, instructors might plan changes they could make to their teaching. In the next semester, they might implement and test the strategy. Subsequent semesters could then be used to continue to refine and develop a teaching strategy. Such a scenario took place in several groups of SIMPLE STEM during the first year cycle. These groups dedicated the first semester to learning about new interactive teaching strategies of interest, and in the second semester group members tried these strategies in their classrooms. In a previous paper about SIMPLE Engineering ${ }^{12}$, we reported on the experience of one of our participants who spent two years gradually shifting from a lecture-based instructional model to using in-class problem solving as a large portion of his class. This example illustrates that change to teaching can take several semesters. An implication for research in this area is that studies that include student outcomes early in the adoption of a teaching strategy may be capturing the early design phases without giving instructors time to be more comfortable with interactive teaching. The impacts on students' learning may not be realized until later semesters.

A final shared theme across groups in the two projects is the value of sharing both evidence-based strategies and personal experiences using these strategies. While several pockets of interest in interactive teaching exist within the institution in which SIMPLE STEM takes place (e.g. several active and collaborative classrooms and an office focused on undergraduate scholarship), there is no united front advancing evidence-based teaching. In SIMPLE STEM, departments vary in their support for interactive teaching. Some instructors are working on their own teaching, and other instructors are within departments that have more support for collaborative change. As an example, some groups included participation by the department chair, which we view as a sign of evolving institutional support. The SIMPLE groups provide a mechanism for sharing interactive teaching ideas and experiences to smooth the design process. As one faculty participant stated in an interview,

"The most beneficial thing was talking with other people in our department, specifically talking about teaching. You know, when we go to faculty meetings or other kinds of meetings, we don't spend our time talking about different ideas or different teaching strategies, we have all kinds of business to do. So, it was nice [that it was] made up of just people who are really focused on their teaching and wanted to make improvements. And then we talked about different techniques that had worked or hadn't worked in the past. It was beneficial for me because... this was my second year teaching. So, I got to talk with my colleagues that had had more years of experience doing this, they had more ideas or more things that they've tried in the past and can say, well, that worked and that didn't work."

\section{Variation across Projects and Groups}

Across both SIMPLE Engineering and SIMPLE STEM, the teaching development groups varied significantly in the frequency, structure, and content of their meetings. Groups 
across the two projects met anywhere from weekly to every six weeks. The meeting variation was driven by the needs of the groups and their collective and individual goals. For one group in which each member was implementing and assessing a different technique, meeting only once every six weeks allowed them to touch base and keep their support structure without taking time away from their change efforts in the classroom. Groups also varied in terms of the roles (job titles) of participants. Some groups included primarily a mix of term/teaching and tenure-line faculty, while others included primarily term/teaching faculty, and still others included a mix of faculty and graduate students. The composition of groups was often related to the role of the group leader and to leader's recruitment choices in populating the group. In some cases, groups were formed around faculty who taught similar or related courses, while others were formed around the faculty most interested in improving their teaching.

The role of graduate students has also been varied. As mentioned above, knowledge gained through SIMPLE Engineering pointed to the importance of understanding the possible participation of graduate students in teaching development. Three groups (one from the Engineering project and two from the first year cycle of the STEM project) have included both faculty and graduate teaching assistants. In the case of SIMPLE Engineering, one graduate student who was fully responsible for a course participated in a group otherwise composed of faculty. In the case of SIMPLE STEM, some of the groups included both faculty and graduate student participants. In these groups graduate students were productive and helpful members of the group and brought their own ideas to the table but also benefitted from the opportunity to be mentored by the faculty. As one group leader described the role of a graduate student participant, "He is... a graduate teaching assistant fairly interested in teaching and education stuff, had some interesting ideas of how we can work with TAs, better to train them... they do a lot of the lab teaching." From the perspective of one SIMPLE STEM graduate student, "In [my] group it was a combination of faculty members and graduate students. [...]. I think that I gained from their [faculty's] insight, absolutely. Yeah, I don't know if faculty members gained from our insight [laughing]. But I benefitted absolutely.” Some current group leaders are thinking about creating a separate group that would consists of solely graduate students; these leaders hypothesize that having their own space would be more comfortable for students. These diverse options for graduate student involvement allow departments to consider what makes the most sense for them and how to support the teaching development of the graduate students providing instruction in their classrooms and labs.

Another difference observed between groups across the two projects is the extent to which meetings were structured and the variety of meeting structures. In SIMPLE Engineering, groups valued structure and scaffolding in the group meetings. Going into SIMPLE Engineering the groups were open-ended, but a common comment from the group leaders was that their groups felt more successful and effective when the meetings became focused around particular topics and/or resources. For some groups, this meant reading a book on effective teaching and discussing particular chapters, while for others it meant watching and discussing videos about teaching or framing a discussion around particular interventions or technologies of interest. In SIMPLE STEM, mixed results were found regarding the structure. Indeed, the groups varied in meeting structure from 
completely unstructured (flowing discussion) to rigidly structured (with a specific focus or agenda) with different participants valuing different ways of meeting organization. Nevertheless, group leaders in both projects predominantly described their roles as facilitators who scheduled and structured the meetings, provided resources, and then facilitated discussion.

An important change from the SIMPLE Engineering to the SIMPLE STEM project was the expansion to several STEM disciplines and the mutual support of all groups on a single campus. We have observed that having a diverse set of groups on a single campus has facilitated participants' interest in broader sharing of ideas and experience between groups. For example, one of group members stated, "We'd like to know what happens in other departments, other schools. [...]. Not necessarily sit down in one room and talk about it. I think that is too time-consuming. But if you can summarize what other people are doing in simple materials and disseminate, that would be very helpful.” Another way of disseminating "teaching wisdom" across departments is through the design memos mentioned earlier in this paper. We are beginning to create an online repository of design memos accessible for any instructor. Overall, this evidence points to the importance of scaffolding connections, not just within departments but also across departments, as a means to broadly support interactive teaching.

\section{Discussion and Open Questions}

Our experience with faculty development groups in SIMPLE Engineering provided the basis for the development of the SIMPLE principles. Expansion to multiple STEM fields within a single university has provided (and continues to provide) the context to expand the interpretation and operationalization of the principles. As the teaching design process is iterative, so too is the process of structuring and scaffolding effective faculty development groups. Our theory of change with SIMPLE is that starting with instructors (including graduate students) who are receptive to change is the first step toward interactive instruction becoming a more common practice. Consistent with diffusion of innovation principles ${ }^{15}$ finding the "early adopters" and those who are most receptive to change is one strategy for broader adoption of innovation. The SIMPLE groups provide a space for instructors interested in interactive teaching to connect with one another and support each other in what they are doing. This is part of the sustainability and peopledriven aspect of the work. At this stage, our projects have had only one-to-two years to develop, and it remains to be seen what the ongoing implications might be of the SIMPLE groups as they continue to evolve and as new groups form.

In SIMPLE STEM, some groups have selected a common teaching strategy or course setting as a goal for their group, while other groups have selected an overarching group goal while adopting different strategies that supported that goal in their classrooms. We do not anticipate one model to be superior to the other, but instead propose that these are variations on the common theme of professional learning communities for faculty teaching development. Groups are also interested in learning more from each other, so creating forums in which participants can discuss their work with other groups is a potential direction for investigation. In terms of institutional change, some groups have 
included department chairs or leaders, which may have an impact on the long-term sustainability and support.

\section{Acknowledgements}

This material is based upon work supported by the National Science Foundation under Grants No. 1347675 (DUE) and No. 0835919 (EEC) and while the second author served as a program officer at the National Science Foundation. Any opinions, findings, conclusions, or recommendations expressed in this material are those of the authors and do not necessarily reflect the views of the National Science Foundation.

\section{References}

1. National Research Council. Discipline-based education research: Understanding and improving learning in undergraduate science and engineering. (The National Academies Press, 2012).

2. Cox, M. \& Harris, A. Comparison of pretenured and tenured engineering professors' pedagogical practices within undergraduate bioengineering courses. Int. J. Scholarsh. Teach. Learn. 4, 1-11 (2010).

3. Light, G., Calkins, S., Luna, M. \& Drane, D. Assessing the impact of a year-long faculty development program on faculty approaches to teaching. Int. J. Teach. Learn. High. Educ. 20, 168-181 (2008).

4. McKenna, A. K., Yalvac, B. \& Light, G. J. The role of collaborative reflection on shaping engineering faculty teaching approaches. J. Eng. Educ. 98, 17-26 (2009).

5. Finelli, C. J., Daly, S. R. \& Richardson, K. M. Bridging the research-to-practice gap: Designing an institutional change plan using local evidence. J. Eng. Educ. 103, 331-361 (2014).

6. Wenger, E. Communities of practice: Learning, meaning, and identity. (Cambridge University Press, 1999).

7. Anderson, O. S. \& Finelli, C. J. A faculty learning community to improve teaching practices in large engineering courses: Lasting impacts. in Proceedings of the 121st ASEE Annual Conference (2014).

8. Zemke, D. \& Zemke, S. Using a community of practice to diffuse instructional improvements into the classroom. in Proceedings of the 121st ASEE Annual Conference (2014).

9. Hjalmarson, M. A. \& Nelson, J. K. Creating small interactive teaching groups. in Proceedings of the 121st ASEE Annual Conference (2014).

10. Laurillard, D. Teaching as a design science: Building pedagogical patterns for learning and technology. (Routledge, 2012).

11. Nelson, J. K. \& Hjalmarson, M. A. Faculty Development Groups for Interactive Teaching. in Proceedings of the 122nd ASEE Annual Conference (2015).

12. Hjalmarson, M., Nelson, J. K. \& Lorie, C. Teaching as a design process: a framework for designbased research in engineering education. in (2015).

13. Hjalmarson, M. A. et al. Developing interactive teaching strategies for electrical engineering faculty. in Proceedings of the 120th American Society of Engineering Education Conference (2013).

14. Merriam, S. B. Qualitative research and case study applications in education. (Jossey-Bass, 2001).

15. Rogers, E. Diffusion of Innovations. (Free Press, 2003). 